\title{
Nano-structured zinc oxide-cotton fibers: synthesis, characterization and applications
}

\author{
Issa M. El-Nahhal · Shehata M. Zourab • Fawzi S. Kodeh • \\ Abdelraouf A. Elmanama • Mohamed Selmane • \\ Isabelle Genois • Florence Babonneau
}

Received: 30 April 2013/ Accepted: 13 June 2013/Published online: 22 June 2013

(C) The Author(s) 2013. This article is published with open access at Springerlink.com

\begin{abstract}
Zinc oxide nanoparticles were prepared and subsequently deposited onto the surface of the cotton fiber by ultrasonic irradiation. The optical, structure and morphology of the coated and un-coated cotton were examined by UV, fourier transform infrared spectroscopy, X-ray diffraction analysis (XRD) and scanning electron microscope (SEM)/Energy Dispersive X-ray analysis. XRD analysis revealed the presence of the crystalline metal oxide of hexagonal phase with an average crystallite size of $12 \mathrm{~nm}$. These nanoparticles are probably physically adsorbed onto the cotton fiber surface. SEM analysis showed a distribution of $\mathrm{ZnO}$ nanorod assemblies of various diameters and lengths physically adsorbed onto the cotton fiber surface may take place. The $\mathrm{ZnO}$-cotton fiber nano-composite were tested against Escherichia coli (gram negative) and Staphylococcus aureus (gram positive) cultures, and showed a significant antimicrobial activity.
\end{abstract}

I. M. El-Nahhal $(\bowtie) \cdot$ S. M. Zourab · F. S. Kodeh

Department of Chemistry, Al-Azhar University,

P.O. Box 1277, Gaza, Palestine

e-mail: issanahhal@hotmail.com

\section{A. A. Elmanama}

Department of Medical Technology, Islamic University-Gaza, P.O. Box 108, Gaza, Palestine

M. Selmane - I. Genois - F. Babonneau

Laboratoire de Chimie de la Matière Condensée de Paris,

Université Piere Curie-Paris 6, 75231 Paris, France

M. Selmane · I. Genois · F. Babonneau

CNRS, College de France, 11 Place Marcelin Berthelot,

75231 Paris, France

\section{Introduction}

Zinc oxide ( $\mathrm{ZnO})$, with a wide band gap of $3.4 \mathrm{eV}$ and a large exciton binding energy of $60 \mathrm{meV}$, has attracted considerable attentions and is recognized as one of the most promising semiconductor materials in electronic and photonic applications [1]. Preparation and applications of nano metal oxide coatings onto cotton and glass substrates have received much attention in recent years due to its promising applications [2-9]. There is a growing awareness of the use of antibacterial fabrics in the form of medical clothes, protective garments, and bed spreads to minimize the chance of the nosocomial infections [10]. Nanoparticles are much more active than larger one because of their higher surface area and they display unique physical and chemical properties [11]. Textiles coated with silver nanoparticles have become quite common [12]. $\mathrm{ZnO}$ nanoparticles is very efficient in impart of antibacterial effect to fabric [13, 14], they are currently being tested as antibacterial agent against Escherichia coli (gram negative) and Staphylococcus aureus (gram positive) cultures. An important aspect of the use of $\mathrm{ZnO}$ as antibacterial agent is the requirement that the particles are not toxic to human cell $[15,16]$. Although the exact mechanism has not yet been clearly elucidated, the suggested mechanisms include: the role of reactive oxygen species (ROS) generated on the surface of the particles [15] zinc ion release [16] and formation of $\mathrm{H}_{2} \mathrm{O}_{2}$ [17] remain possibilities.

There were two general routes to impregnated $\mathrm{ZnO}$ nano particles onto the cotton fiber, the first route in which the prepared $\mathrm{ZnO}$ nano crystals, were coated onto cotton fibers simply by cure process [6]. The second route was to use the ultrasonic irradiation as an effective method for the deposition of nano materials onto the surface of cotton fibers and other substrates [5, 18-24]. Perelshtein and others have previously used the second route to impregnated some 
metal oxides ricated nanoparticles onto fabricated cotton materials [5]. In this research the $\mathrm{ZnO}$ nanoparticles were impregnated and deposited on/into the natural cotton fibers by irradiation of ultrasound vibrations, so many multiapplications could be addressed. In our previous article we reported the preparation of nanopartiles $\mathrm{CuO}$-coated cotton composite and its application [24]. The aim of the present research was to produce $\mathrm{ZnO}$ nanoparticles coated onto nature cotton fibers and to estimate its antibacterial properties against $E$. coli and $S$. aureus. $\mathrm{ZnO}$ nanoparticles act as antibacterial agent, while cotton act as a substrate which can be used to fabricat medical clothes. Scanning electron microscope (SEM) and X-ray diffraction analysis (XRD) were used to reveal information about the sample, including external morphology, chemical composition, and crystalline structure and orientation of materials making up the sample. Energy dispersive X-ray (EDX) was applied to identify the atomic percentage contents of the main formulation's elements, that has been applied in coating using EDX unit connected to the SEM microscope. Fourier transform infrared spectroscopy (FTIR) and UV-Visible spectra were used to confirm the formation of $\mathrm{ZnO}$ nanoparticles onto the cotton fibers.

\section{Experimental}

\subsection{Materials and instrumentals}

Zinc sulfate, sodium hydroxide and ethanol were purchased from MERCK and used without further purification. Cotton was purchased from local market as an Egyptian cotton product. The UV spectra of $\mathrm{ZnO}$ were recorded on a SHIMADZU-1601 UV-VIS spectrophotometer in the range 200-800 $\mathrm{nm}$. The infrared spectra for the $\mathrm{ZnO}$ coated materials were recorded on a SHIMADZU-1802 FTIR spectrophotometer, using $\mathrm{KBr}$ disk in the range $4,000-400 \mathrm{~cm}^{-1}$. Chemical analysis of the $\mathrm{ZnO}$-coated cotton fibers was obtained by Energy Dispersive X-ray spectroscopy (EDX) using an Oxford on X-Max (area:20 $\mathrm{mm}^{2}$ ) detector installed on a Hitachi S3400N Scanning Electron Microscope (SEM). Calibration of the instrument was performed on $\mathrm{Ti} \mathrm{Ka}$ at $4.509 \mathrm{keV}$. Powder X-ray diffraction (XRD) study was performed on a Bruker D8 Advance Diffractometer using $\mathrm{Cu}-\mathrm{K} \alpha$ radiation $(\lambda=0.15418 \mathrm{~nm}$ at $45 \mathrm{kV}$ and $40 \mathrm{~mA}, 0.05$ step size and $60 \mathrm{~s}$ step time over arrange of $0^{\circ}$ to $80^{\circ}$.

\subsection{Coating procedure}

Cotton fibers were first washed in a water bath containing $5 \%$ of sodium dodecyl sulfate (SDS) at $40{ }^{\circ} \mathrm{C}$ for an hour. After rinsing with distilled water, the fibers were dried in vacuum at $60{ }^{\circ} \mathrm{C}$ for $24 \mathrm{~h}$. The $\mathrm{ZnO}$-coated cotton material were prepared as follows: $0.05 \mathrm{~g}$ dry cotton was first soaked into $10 \mathrm{ml}$ of distilled water containing $0.12 \mathrm{~g}$ of $\mathrm{ZnSO}_{4} \cdot 5 \mathrm{H}_{2} \mathrm{O}$ solution in a sonicated flask and irradiated for 10 min with Ultrasonic Senerator Model US-150 Ti-horn (20 kHz, output 10 Turning 7). $0.06 \mathrm{~g}$ of $\mathrm{NaOH}$ was added to the mixture under stirring. The mixture was then resonicated at $35-40{ }^{\circ} \mathrm{C}$ for one hour. The bath temperature was kept at a constant temperature around $40{ }^{\circ} \mathrm{C}$. The product was then washed thoroughly several times with distilled water to remove any excess of hydroxide and dried in vacuum at $60{ }^{\circ} \mathrm{C}$ overnight. The Zinc concentration in the fiber was determined by titration method (3-4 wt \%).

\subsection{Antibacterial activity screening}

The antimicrobial activity of cotton coated with $\mathrm{ZnO}$ nanoparticles was tested against gram negative and gram positive bacteria. A small piece of cotton coated with $\mathrm{ZnO}$ nanoparticles was added to a tube containing $5 \mathrm{ml}$ of freshly prepared brain heart infusion broth BHIB, (HiMedia, India) that is inoculated with $E$. coli and S. aureus (these are clinical isolates were kindly provided by the Microbiology laboratory of Al-Shifa hospital). The tubes were incubated at $37{ }^{\circ} \mathrm{C}$ for $24 \mathrm{~h}$. The turbidity of the test tubes was compared visually to an uninoculated (control) BHIB tube. $100 \mu \mathrm{l}$ of each tube was diluted and fractions were plated on Nutrient Agar plates and incubated at $37{ }^{\circ} \mathrm{C}$ for $24 \mathrm{~h}$. Colony forming units $/ \mathrm{ml}$ was calculated by multiplying the number of colonies by the dilution factor.

\section{Results and discussion}

\subsection{Synthesis}

The $\mathrm{ZnO}$-coated fibers were obtained by deposition of $\mathrm{ZnO}$ nanoparticles onto the cotton fibers via the ultrasound irradiation of metal hydroxide according to the reaction:

$\mathrm{Zn}^{2+}+4 \mathrm{OH}-\rightarrow \mathrm{Zn}(\mathrm{OH})_{4}^{2-}$

$\mathrm{Zn}(\mathrm{OH})_{4}^{2-} \rightarrow \mathrm{ZnO}+\mathrm{H}_{2} \mathrm{O}+2 \mathrm{OH}^{-}$.

During the formation process, the fresh product $\mathrm{Zn}(\mathrm{OH})_{2}$ is dissolved immediately with superfluous $\mathrm{OH}^{-}$and $\mathrm{Zn}(\mathrm{OH})_{4}^{2-}$ is formed. According to the phase stability diagram of $\mathrm{ZnO}[22,23]$, the formed $\mathrm{Zn}(\mathrm{OH})_{4}^{2-}$ would change to $\mathrm{ZnO}$ nanoparticles at certain $\mathrm{pH}$ value (between 8.5 and 12.5) of the reaction solution. The $\mathrm{ZnO}$ nanoparticles produced by the reaction were probably physically adsorbed onto the surface of the cotton fibers by the sonochemical microjets resulting from the collapse of sonochemical bubles [5]. These nanoparticles are strongly 
physically adsorbed onto the cotton substrate, since these particles are not removed by several washings. But it is found that some $\mathrm{ZnO}$ nanoparticles which weakly adsorbed onto the cotton fibers are leached out during the first five washings, therefore it is suggested that the coated cotton composite should be washed before drying. They are also very stable at $\mathrm{pH} 3-6$, but they are less stable at $\mathrm{pH}<3$, where most $\mathrm{ZnO}$ particles are reacted with the acidic solution.

\subsection{XRD results}

X-ray diffraction analysis revealed the presence of the crystalline metal oxide on the cotton fibers (Fig. 1). The pattern corresponds to the hexagonal phase of $\mathrm{ZnO}$ [25], however they are rather broad because of the nanosized crystallites. The pattern can be indexed for diffractions from the (10 0 0), (l $\left.\begin{array}{lll}0 & 2\end{array}\right),\left(\begin{array}{lll}1 & 0 & 1\end{array}\right),\left(\begin{array}{lll}1 & 0 & 2\end{array}\right),\left(\begin{array}{lll}1 & 1 & 0\end{array}\right),\left(\begin{array}{lll}1 & 0 & 3\end{array}\right)$ and (112) planes of wurtzite crystals. The lattice parameters a and $\mathrm{c}$ of the samples are calculated using the formula:

$\sin ^{2} \theta=\frac{\lambda^{2}}{4}\left[\frac{4}{3}\left(\frac{h^{2}+h k+k^{2}}{a^{2}}\right)+\frac{l^{2}}{c^{2}}\right]$

$\theta$ is the diffraction angle, $\lambda$ is incident wavelength $(\lambda=0.15406 \mathrm{~nm})$ and $\mathrm{h}, \mathrm{k}$ and $\mathrm{l}$ are all Miller indices. The calculation of the lattice parameters is based on wholespectra fitting method for all peaks by using software. The lattice parameters of coated $\mathrm{ZnO}$ nanoparticles are $\mathrm{a}=\mathrm{b}=$ $0.3249 \mathrm{~nm}$ and $\mathrm{c}=0.52008 \mathrm{~nm}$. Scherer's equation was used to estimate mean crystallite size.

$P=\frac{0.9 \lambda}{\beta \cos \theta}$,

where $P$ is the mean diameter of nanoparticles, $\lambda$ is the wavelength of $\mathrm{X}$-ray radiation source, and $\beta$ is the corrected angular full width at half maximum of the X-ray

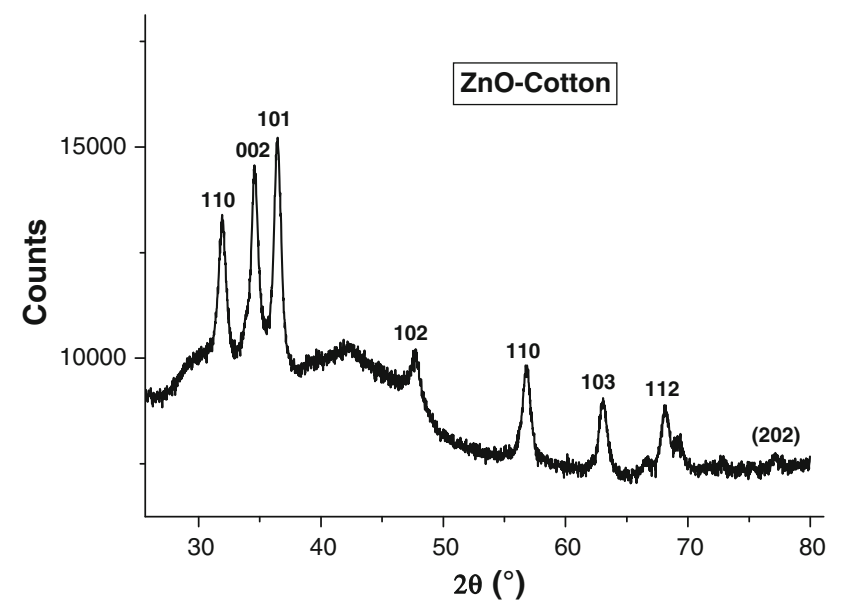

Fig. 1 XRD patterns of $\mathrm{ZnO}$ coated cotton fibers

diffraction peak at the diffraction angle. The average crystallite size of zinic oxide nanoparticles estimated by XRD data was around $12 \mathrm{~nm}$ which is very close to the reported values of similar $\mathrm{ZnO}$ coated cotton materials [4, 26]. The almost very similar calculated crystallite sizes for the five main peaks(Table 1) may provide evidence that a sphere crystallite shape of $\mathrm{ZnO}$ are more probable.

\subsection{SEM and EDX results}

The morphology of the fiber surface before and after deposition of $\mathrm{ZnO}$ nanoparticles was studied by SEM and is presented in Fig. 2. On the SEM image of the original cotton fiber (Fig. 2a), grooves and fibrils could be easily observed on the surface of the fiber. Fig. $2 b$ presents the SEM photographs of $\mathrm{ZnO}$ nanoparticles coated onto cotton fibers after sonication. It is likely to say that, cotton fibers were covered with $\mathrm{ZnO}$ nanoparticles. The SEM analysis revealed that the size of $\mathrm{ZnO}$ nanoparticles coated onto cotton fibers was in the nanoscale range. From Fig. 2a, it is clear that the size of the cotton fibers is in the range of $200 \mu \mathrm{m}$, but the size of the $\mathrm{ZnO}$ nanoparticles coated on the fibers is much smaller of a nanoscale level about $20 \mathrm{~nm}$ as calculated from the ultraviolet spectra. In certain conditions where probably, a slow growth of $\mathrm{ZnO}$ nanoparticles, it is found that nanorod crystals of various sizes as well as assemblies of well defined flower of nanorods of various diameters ranging from 100 to $500 \mathrm{~nm}$ and various length from $500 \mathrm{~nm}$ to few micrometers is clearly showed in SEM image Fig. 2c. That is in agreement with previously reported results [27]. Figure 3 shows the EDX spectra of the $\mathrm{ZnO}$ coated cotton samples. The chemical composition of the $\mathrm{ZnO}$-coated cotton samples are presented in Fig. 3. EDX spectrum of the $\mathrm{ZnO}$ coated cotton composite showed both $\mathrm{Zn}$ and $\mathrm{O}$ components. The presence of $\mathrm{Zn}$ atoms in the coated cotton fibers indicates that $\mathrm{ZnO}$ is deposited onto it.

\subsection{UV-VIS and FTIR spectra}

The structure of the nanoparticles was further examined UV-VIS and FTIR spectroscopy. The UV visible spectrum of the ethanolic solution of $\mathrm{ZnO}$ nanoparticles shows an

Table 1 Crystallite sizes calculated from the peaks 

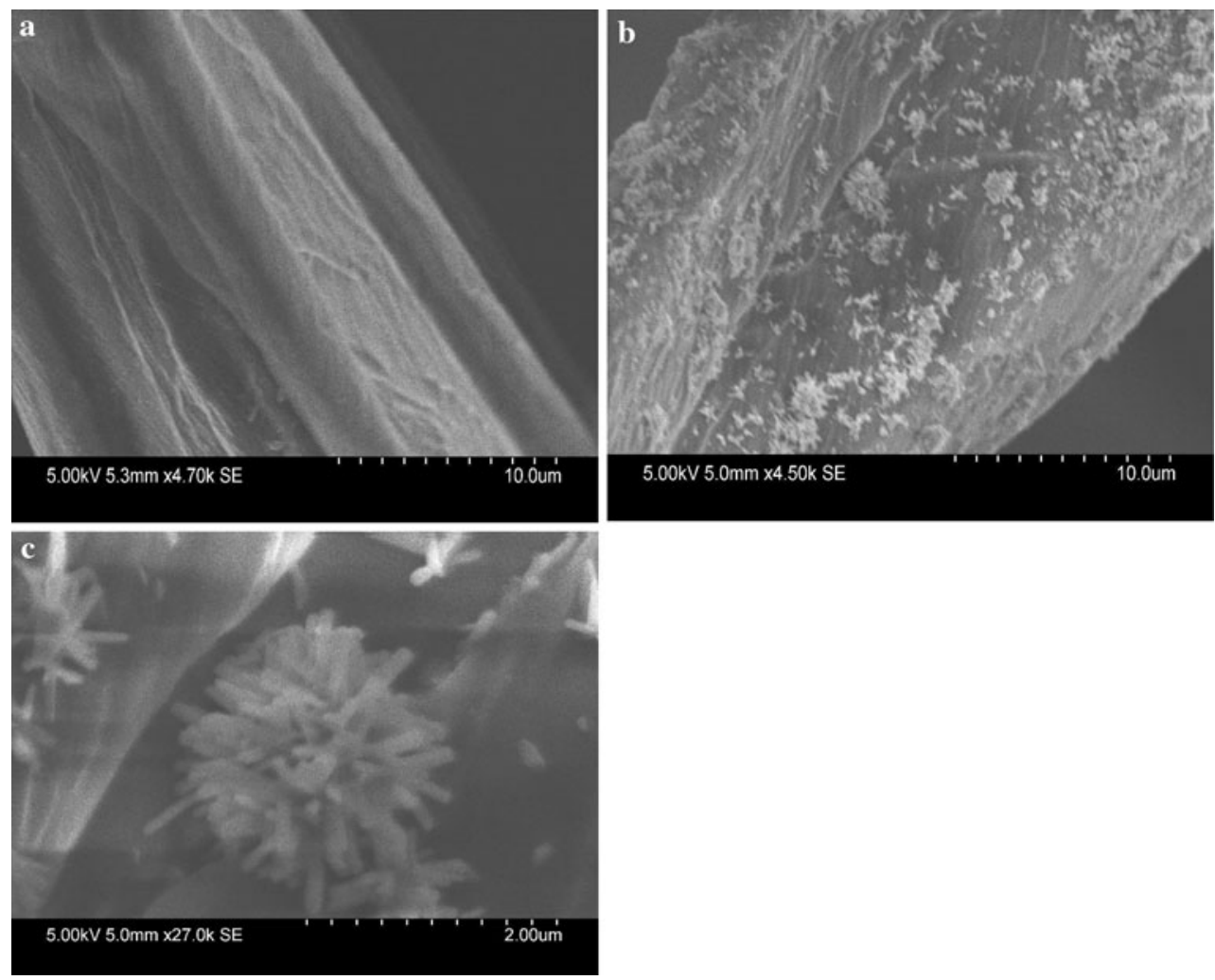

Fig. 2 a SEM image of blank cotton, $\mathbf{b}$ image of nanoparticles of $\mathrm{ZnO}$-coated cotton and $\mathbf{c}$ high magnified image of $\mathrm{ZnO}$ nanorods onto cotton fiber

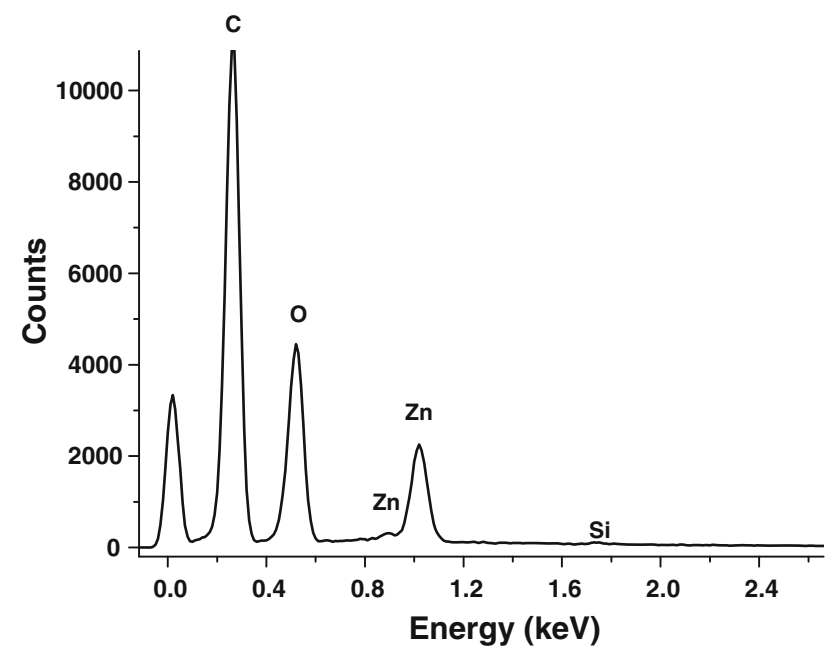

Fig. 3 UV-visible absorption spectrum on nano $\mathrm{ZnO}$ solution

absorption band at $359 \mathrm{~nm}$ (Fig. 4). The energy calculated according to the Planck's constant is $3 \times 4 \mathrm{eV}$. The FTIR spectrum of the immobilized $\mathrm{ZnO}$ nanoparticles coated onto cotton shows an absorption band at $465 \mathrm{~cm}^{-1}$ is typically due to the lattice vibrations of $\mathrm{Zn}-\mathrm{O}$ bond, The strong band at $1,090 \mathrm{~cm}^{-1}$ can be assigned to asymmetric stretching vibration of $\mathrm{Zn}-\mathrm{O}-\mathrm{Zn}$ bridging. The broad band at $3,435 \mathrm{~cm}^{-1}$ is due the $\mathrm{O}-\mathrm{H}$ stretching and the absorption

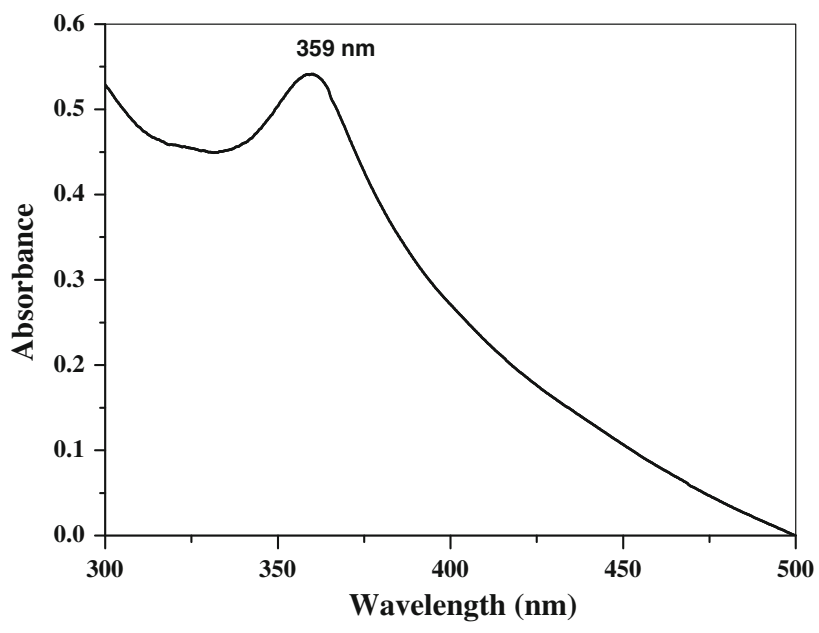

Fig. 4 EDX atomic compositions of $\mathrm{ZnO}$ coated cotton

band at $1,550 \mathrm{~cm}^{-1}$ bending of the hydroxyl groups of some $\mathrm{Zn}(\mathrm{OH})_{2}$ and/or physically adsorbed water molecules [28].

\subsection{Antibacterial activity}

The antibacterial activity of $\mathrm{ZnO}$ nanoparticles coated onto cotton against $E$. coli microorganisms are shown in Fig. 5. The coated cotton sample displays high activity with a 


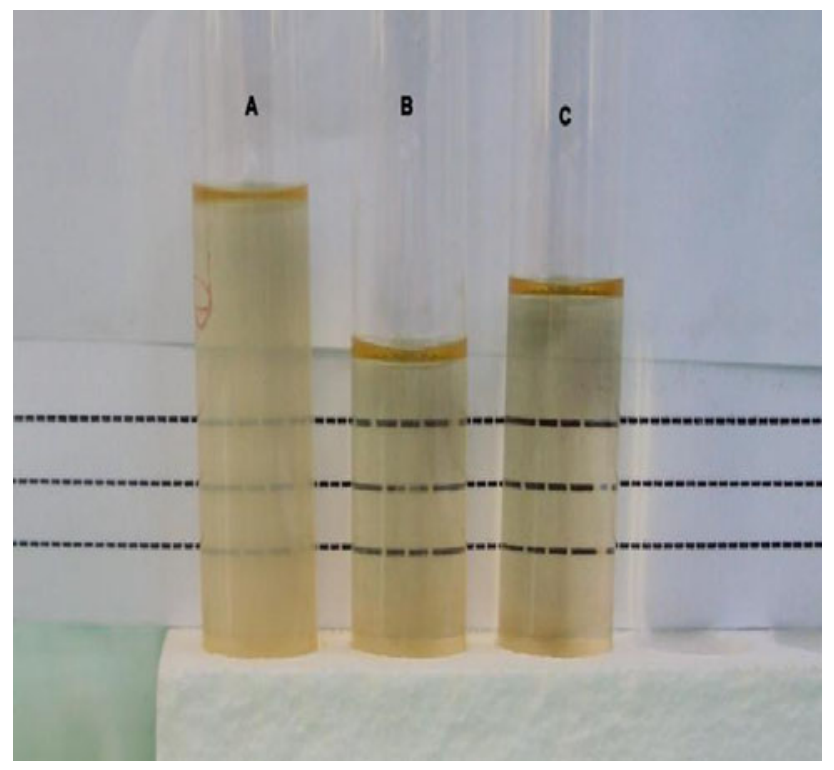

Fig. 5 Photos of antimicrobial activity of $\mathrm{ZnO}$ coated cotton (left positive control; middle sample; right negative control)

Table 2 Antibacterial activity of $\mathrm{ZnO}$ coated cotton against $E$. coli and $S$. aureus

\begin{tabular}{|c|c|c|c|c|}
\hline \multirow[t]{2}{*}{ Treatment } & \multicolumn{2}{|l|}{ E. coli } & \multicolumn{2}{|l|}{ S. aureus } \\
\hline & Tube & Subculture & Tube & Subculture \\
\hline $\begin{array}{l}\mathrm{ZnO} \text { coated } \\
\text { cotton }\end{array}$ & No growth & Negative at $10^{-1}$ & No growth & Negative at $10^{-1}$ \\
\hline
\end{tabular}

great reduction of bacteria (Fig. 5). No growth was observed in the tube containing the $\mathrm{ZnO}$ coated cotton as evident by the clear appearance of the tube and the absence of growth from the subcultured samples. Similar results were observed against $S$. aureus (Table 2).

\section{Conclusion}

$\mathrm{ZnO}$ nanoparticles were deposited onto cotton fibers by ultrasonic irradiation. The morphology and structure of the $\mathrm{ZnO}$ coated cotton fibers were examined by XRD, SEM/ EDX, FTIR and UV visible spectra. XRD analysis revealed the presence of the crystalline metal oxide of hexagonal phase on the cotton fibers. SEM analysis showed that different forms of $\mathrm{ZnO}$ nanoparticles were developed which may be dependent on the chemical conditions; and physical environment during the growing. These materials can be used as antibacterial fabrics in the form of medical cloths, protective garments and bed spreads and other many purposes to minimize the chance of nosocomial infections. Since $\mathrm{ZnO}$ is used in the form of nanoparticle, it will have a very good absorption, penetration and availability. It showed a great reduction in the bacteria activity.

Acknowledgments The authors would like to thank the French Government for the Al-maqdisi grant jointly with the Palestinian Ministry of Higher Education.

Open Access This article is distributed under the terms of the Creative Commons Attribution License which permits any use, distribution, and reproduction in any medium, provided the original author(s) and the source are credited.

\section{References}

1. M.H. Huang, S. Mao, H. Feick, H. Yan, Y. Wu, H. Kind et al., Science 292, 1897 (2001)

2. H. Wang, A. Zakirov, S.U. Yuldashev, J. Lee, F. Dejun, T. Kang, Mater. Lett. 65, 1316 (2011)

3. Gadi Borkow, Jeffrey Gabbay, Curr. Chem. Biol. 3, 272-278 (2009)

4. O.V. Abramov, A. Gedanken, Y. Koltypin, N. Perkas, I. Perelshtein, E. Joyce, T.J. Mason, Surf. Coat. Technol. 204, 718-722 (2009)

5. I. Perelshtein, G. Applerot, N. Perkas, E. Wehrschetz-Sigl, A. Hasmann, G. Guebitz, A. Gedanken, Surf. Coat. Technol. 204, 54 (2009)

6. S. Sule, M. Sarnsik, A.H. Aktas, M.C. Ucar, E. Erden, Nanoscale Res. Lett. 5, 1204-1210 (2010)

7. B. Xu, Z. Cai, Appl. Surf. Sci. 254, 5899-5904 (2008)

8. J. Zhao, Z.G. Jin, T. Li, X.X. Liu, Appl. Surf. Sci. 252, 8287 (2006)

9. N. Neamjan, W. Srichanussn, P. Threepopnatkul, J. Nanosci Technol. 12, 525 (2012)

10. S. Wang, W. Hou, L. Wei, H. Jia, X. Liu, B. Xu, Surf. Coat. Technol. 202, 460-465 (2007)

11. C.Y. Chen, C.L. Chiang, Materials Lett. 62, 3607-3609 (2008)

12. N. Duran, P.D. Marcarto, G.I.H. De Souza, O.L. Alves, E. Esposito, J. Biomed. Nanotechnol. 3, 203-208 (2007)

13. G. Applerot, A. Lipovsky, R. Dror, N. Perkas, Y. Nitzan, R. Lubart et al., Adv. Funct. Mater. 19, 1-11 (2009)

14. Z. Huang, X Zheng, D Yan, G Yin, X Liao, Y Kang, et al., Langmuir 15, 4140-4144. J. Nanoparticle Res. 9, 479-489 (2008)

15. S. Nair, A. Sasidharan, VV. Divya Rani, D. Menon, S. Nair. K. Manzoor, J. Mater. Sci. Mater. Med. (2008) (online first).

16. J. Sawai, E. Kawada, F. Kanou, H. Igarashi, A. Hashimoto, T. Kokugan et al., J. Chem. Eng. Jpn. 29, 627-633 (1996)

17. J. Sawai, H. Kojima, H. Igarashi, A. Hashimoto, S. Shoji, A. Takehara et al., J. Chem. Eng. Jpn. 30, 1034-1039 (1997)

18. J. Sawai, S. Shouji, H. Igarashi, A. Hashimoto, T. Kokugan, M. Shimizu et al., J. Ferment. Bioeng.86, 521 (1998)

19. A. Gedanken, Ultrason. Sonochem. 11, 47 (2004)

20. V.G. Pol, G. Wildermuth, J. Felsche, A. Gedanken, J. CalderonMoreno, J. Nanosci. Nanotech. 5, 975 (2006)

21. V.G. Pol, A. Gedanken, J. Calderon-Moreno, Chem. Mater. 15, 1111 (2003)

22. N. Perkas, G. Amirian, S. Dubinsky, S. Gazit, A. Gedanken, J. Appl. Polym. Sci. 1042, 1423 (2007)

23. R.H. Wang, J.H. Xin, X.M. Tao, W.A. Daoud, Chem. Phys. Lett. 398, 250 (2004)

24. I.M. Elnahhal, S.M. Zourab, F. Kodeh, F. Babonneau et al., Intern. Nano Lett. 2, 62 (2012) 
25. O. Garcia-Martinez et al., Solid State Ionic 63, 442 (1993)

26. S. Yamabi, H. Imai, J. Mater. Chem. 12, 3773 (2002)

27. A. Bagreev, S. Bashkova, D.C. Locke, T.J. Bandos, Environ Sci Tech 35, 1537-1543 (2001)
28. M. Yeganeh Ghotbi, J. Alloy. Compd. 491, 420-422 (2010) 